Please quote as: Kleinschmidt, S.; Peters, C. \& Leimeister, J. M. (2016): ICT-enabled service innovation in human-centered service systems: A systematic literature review. In: International Conference on Information Systems (ICIS), Dublin, Ireland. 


\title{
ICT-Enabled Service Innovation in Human- Centered Service Systems: A Systematic Literature Review
}

\author{
Completed Research Paper
}

\author{
Stefan Kleinschmidt 1 \\ stefan.kleinschmidt@unisg.ch
}

\author{
Christoph Peters 1,2 \\ christoph.peters@unisg.ch
}

\author{
Jan Marco Leimeister ${ }^{1,2}$ \\ janmarco.leimeister@unisg.ch \\ ${ }^{1}$ University of St. Gallen \\ Institute of Information Management \\ Unterer Graben 21, 9000 St. Gallen, Switzerland \\ ${ }^{2}$ University of Kassel \\ Research Center for IS Design (ITeG) \\ Pfannkuchstr. 1, 34121 Kassel, Germany
}

\begin{abstract}
In numerous studies, information and communications technology (ICT) has been shown to be an enabler of service innovations in human-centered service systems (HCSSs). The resulting findings, however, have not been presented in a systematic way. Therefore, we present an integrated and representative overview of the literature on ICT-enabled service innovation in HCSSs. To show the existing findings, we reviewed papers from top journals in the fields of management science, information systems, service research, and innovation management. By using a systematic literature review, we identified 37 relevant papers. We systematically assessed the papers based on an analytical framework that consists of a four-phase management process and the components of service systems. We showed that the research background and the research methods used in the papers are very diverse, representing a large research field with a varying degree of knowledge. Based on our findings, we derived a specific agenda for future research.
\end{abstract}

Keywords: Service Innovation, Human-Centered Service Systems, Service Science, Literature Review, Research Agenda

\section{Introduction}

Service is the fundamental basis of exchange and has an enormous economic importance (Vargo and Lusch 2004). Data from the world bank (2016) confirm this. This economic relevance can also be translated to the individual level. Human-centered service systems (HCSSs), which focus on human interaction and personal service, are of great importance because they cover areas that are essential for our society and our everyday life such as healthcare or education. Every company and individual should be interested in well-functioning and advanced service systems in these domains. Compared to this economic and practical relevance, relatively little is known regarding this research context (Maglio et al. 2015). 
Service innovations, defined as service system reconfigurations (Breidbach and Maglio 2015), are the basis of an improved value-creation process. The aim of such service innovations is to change service systems in a way that increases the value for the involved actors. The rapid advancements and diffusion of information and communication technology (ICT) contribute to many of these service innovations (Bitner et al. 2000; Davis et al. 2011). ICT enables service processes to become more efficient and effective. In some cases, it also allows the exploitation of new areas of business (Barrett et al. 2015). This rise of ICT in service innovation means a development toward a digital economy (OECD 2015). Unfortunately, HCSSs are difficult to digitize, because they focus on human interaction and are thus labor intensive and not standardized (Spohrer et al. 2007). However, their diffusion makes HCSSs enormously relevant for companies (Maglio et al. 2015). In summary, the following literature review focuses on service innovations in HCSSs that leverage ICT to advance service systems.

Both research and business practices recognized the potential of ICT-enabled service innovation in HCSSs. In research, the service-dominant logic (Vargo and Lusch 2004, 2016) puts service as the fundamental basis of exchange and proposes value as a cocreation of the interaction between multiple actors. Innovating within complex service systems and value networks is regarded as one of the top research priorities in service research (Ostrom et al. 2015). With ICT as a facilitator and initiator of service innovation and value cocreation, this topic becomes relevant for Information Systems (IS) research because it links human interaction with the technology in the business environment (Lusch and Nambisan 2015; Rai and Sambamurthy 2006; Yoo et al. 2012). In business practice, especially innovative companies observe opportunities to improve and support complex and human-based processes. Apple Inc. (2016) presents a successful example. They encourage teachers to use their products to enhance the learning experience for students. Although the focus of the service system is still on education, ICT improves the teaching abilities and the learning experience for the students and thus improves the value of the service systems. Previous findings on ICT-enabled service innovation in HCSSs are not presented systematically. Given the significance of the topic, further research is desirable (Maglio et al. 2015; Sheehan 2006). Therefore, a systematic summary of the literature is required, which is not available yet.

This literature review presents an integrated and representative overview of the literature on ICT-enabled service innovation in HCSSs and provides opportunities for future research. By showing the state of the art for research on ICT-enabled service innovation, this literature review includes three contributions. First, we present conceptualizations for both, HCSSs and ICT-related service innovations. Thus, we promote further understanding in those areas for researchers and practitioners. Second, we develop an analytical framework for the assessment of the found literature. We thereby provide a simple and condensed insight into previously conducted research. Third, we discuss the findings and show emerging research gaps. Thereby, we give starting points for further research.

The paper is structured as follows: The next section provides a theoretical background of HCSSs and ICTenabled service innovation, which will define the key terms and concepts relevant to these fields. The third section describes the actual review process, providing insights into the methodology used for this systematic literature review. The fourth section contains the findings on a descriptive and thematic level. Based on the discussion of the findings, in the fifth section, a research agenda is derived including interesting topics for future research (Rowe 2014). The sixth section addresses limitations, and the last section provides an overall conclusion of the paper.

\section{Theoretical Background}

\section{Human-Centered Service Systems}

In line with the service-dominant logic, this literature review understands service as a process cocreating a context-specific value (Vargo and Lusch 2004, 2016). This process takes place in service systems because it includes several participants, with one of them being the beneficiary (Vargo and Lusch 2016). These service systems are "configurations of people, information, organizations, and technologies that operate together for mutual benefit" (Maglio et al. 2015, p. 2). Capabilities, interaction, change, and engagement are fundamental to service systems. However, because we investigate the role of IT-enabled service innovation this definition of service system emphasizes on technology rather than on the more general role of institutions (Vargo and Lusch 2016). The example from the introduction may serve as an illustration of a service system. In the learning environment, the value cocreation, meaning the teaching and transfer of 
information to the student leading to according competencies, does not happen by itself. It requires a knowledge source and a way of communicating this knowledge to the student in a structured and thoughtful way. In a classical school environment, this is provided by the teacher, curriculum, and appropriate infrastructure (including ICT). In this case, the students are the beneficiaries who - by their active involvement - cocreate the learning service.

HCSSs, which are service systems with a focus on human interaction and personal service, require special attention (Maglio et al. 2015). They differ from other service systems because the personal interaction between the different actors is essential for the value creation. This is the case in diverse industries such as hospitality, healthcare, retail, finance, government, and infrastructure, but not limited to these (Maglio et al. 2015; Peters 2016). The more a service system depends on knowledge and customization to the beneficiary needs, the higher is the value cocreation of all actors in the service system (Maglio and Spohrer 2008). This has two opposite effects for HCSSs. On the one hand, it allows the service personnel to react individually to specific situations and thereby improve the service output. On the other hand, the customer contact theory suggests that the potential efficiency of highly interactive service systems is "a function of the degree to which the customer is in direct contact with the service facility relative to total service creation time for the customer" (Chase 1981, p. 700). Therefore, these service systems are complex adaptive systems that are not necessarily planned in advance (Barrett et al. 2015; Spohrer et al. 2007). As interaction is critical to the value creation, the leveraging of ICT for service innovations in this area can have a huge potential for changing the way how HCSSs work.

\section{ICT-Enabled Service Innovation}

Based on Breidbach and Maglio (2015), we define service innovation as a reconfiguration of a service system with the aim to increase the value of the service system. This view includes that service innovation can be a process as well as an outcome. One or more parts of a service system - people, information organizations, technologies - can be replaced or changed to increase the value (Breidbach and Maglio 2015; den Hertog et al. 2010). Thereby, ICT is one of the most discussed dimensions of innovation (Breidbach and Maglio 2015; Lusch and Nambisan 2015; Peters et al. 2016). Existing disagreement concerns whether ICT use in service systems initiates and/or enables service innovations by improving the integration of resources and value cocreation. Ryu et al. (2014) examined this question and found that ICT is rather a dimension of a service innovation than an operant resource or a mediator. Coming back to the example of the classical school environment, a service innovation consists of changing the infrastructure by adding ICT. With the ICT, students become more interested in the course contents before, during, and after the classes. The objective of the service system has remained the same, but the value cocreation changed. As a result, the value for the students and teachers has changed and improved.

In reference to the example, there is a difference between ICT service innovations and ICT-enabled service innovation. Based on emerging trends such as an increase in self-service and automation, there is an expansion of ICT in service systems (Davis et al. 2011). To a large extent, the analysis of service innovation is centered on ICT artifacts instead of service systems (Breidbach and Maglio 2015; Peters et al. 2016). For example, with their contribution, Ryu et al. (2014) examined whether ICT is the focus of service innovation or an integrated part of it. The integration of different actors in the service system is challenging as ICT can substitute employees (Ostrom et al. 2015), which implies different adoption processes (Peters et al. 2015). This insight is especially relevant for HCSSs as personal interactions are essential for the value creation (Kleinschmidt et al. 2016). An innovation toward a technology-centered service system will change the entire service (Bitner et al. 2000). Individual behaviors and actions that create value have changed. Therefore, in HCSSs, ICT and people should be regarded as an integral part of the ICT-enabled service innovation (Maglio 2015). Referring to the classroom example, this means that the value creation cannot be centrally improved by simply adding tablets, computers, or software, but by the integration of this service system.

\section{Methodology}

The purpose of this literature review is to present an integrated and representative overview of the literature on ICT-enabled service innovations in HCSSs and to provide opportunities for future research. Therefore, we applied the methodology of Webster and Watson (2002) and vom Brocke et al. (2009, 2015) to prepare this review. The scope of this literature review focuses on data collection and analysis (Cooper 1988; Jennex 
2015). The focus on data collection is reflected in the inclusion criteria and selected journals. The analysis includes a descriptive as well as scoping analysis (Paré et al. 2015).

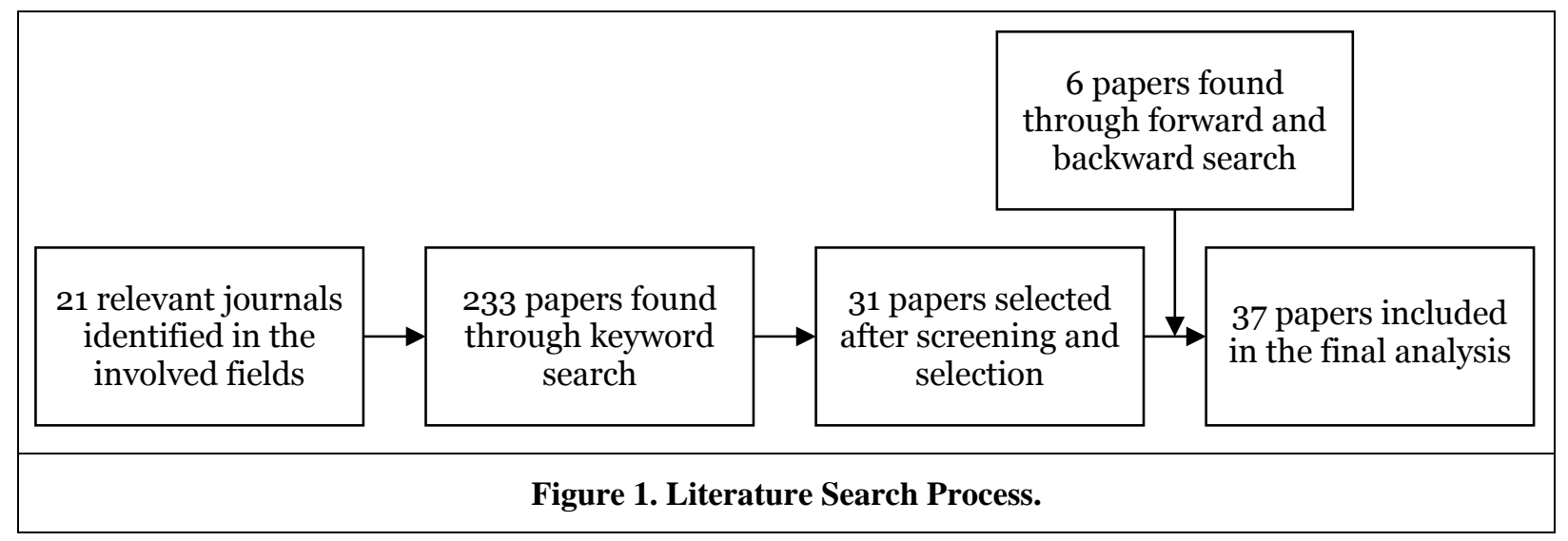

The search process for this literature review contained four steps before including the papers in the analysis. The process is depicted in Figure 1. The literature on ICT-enabled service innovation and HCSSs is multidisciplinary (Huang and Rust 2013; Maglio et al. 2015). Therefore, following Webster and Watson (2002), this review started with literature from top journals in the fields of management science, information systems, service research, and innovation management. Suitable journals that provide an overview of high-quality and relevant research in the respective fields were selected using the objective Thomson Reuters Journal Citation Report and the subjective German VHB-JOURQUAL 3 ranking. We searched in each journal using the search parameters ("information technology" OR "information and communications technology" OR digitization) AND innovation AND ("service system" OR "service systems"). The search parameters were chosen as they represent the combination of innovation in service systems via ICT. The particular terms cover both singular and plural and are based on the terms used regarding the theoretical background. Since the various databases have different formats, adaptations to the specific search strings were made. 233 papers were found through the keyword search ("Hits" in Table 2). The sources were chosen depending on the number of hits, preferring a larger number of papers (crossjournal databases vs. publishers' databases). In a screening and selection step, the papers were checked regarding their titles and abstracts based on three inclusion criteria. These criteria included a research focus on ICT-enabled service innovation, a research background in the field of HCSSs, and a data collection in the research papers. 31 papers matched these criteria ("Included" in Table 2). Backward and forward searches were performed to identify more relevant literature (Webster and Watson 2002). For the forward search, we used the Thomson Reuters Web of Science research platform. We applied the same inclusion criteria and quality standards. In total, 37 papers were included in the final analysis ("Included" plus "Forward/Backward" in Table 2). The results include papers that were published before 2016.

The analysis of this literature review is based on a systematic information extraction and mapping of the research objectives to an analytical framework. The data extraction for each contribution included the eight different categories of:

- Full reference

- Specific research context

- Studied IT-related service innovation

- Main research objective
- Main research findings

- Theoretical foundation

- Research methods used

- Proposed future research

For the analysis, we introduce a framework integrating two dimensions. The first dimension depicts a service innovation management process that includes four phases. This process builds on work regarding the system development life cycle that is included in ICT-enabled change (Markus 2004) and was applied to service systems (Alter 2008). The management process describes the phases before, during, and after an ICT-enabled service innovation. The different process phases contain activities that build on each other. The initial phase is about understanding the innovation process and its influencing factors. Based on this knowledge the idea of the service innovation is questioned and the decision is made for the implementation. The second phase includes the development of the ICT-enabled service system and thus the core of the service innovation. In the end, a running service system offers value to the beneficiary. The activities after 
the ICT-enabled service innovation are divided into two phases. The third phase includes aspects that are connected with the operation of the service system. Here, the actual value cocreation is started, and possible adaptions are implemented. The goal is to reach a state of stable operations. The final phase includes the value capture for the company. Here, the value cocreation is established and the and that can take an assessment of the ICT-enabled service innovation. Table 1 depicts a summary of the phases and their associated descriptions.

\begin{tabular}{|l|l|}
\hline \multicolumn{2}{|c|}{ Table 1. Phases of the Service Innovation Management Process. } \\
\hline Phase & Description \\
\hline Understanding & $\begin{array}{l}\text { Idea to Decision - Understanding what needs to be considered for and what is } \\
\text { included in an ICT-enabled service innovation. }\end{array}$ \\
\hline $\begin{array}{l}\text { Designing \& } \\
\text { Implementing }\end{array}$ & $\begin{array}{l}\text { Decision to Service System - Execution of the service innovation including the } \\
\text { building or acquisition of the ICT and the most appropriate service system } \\
\text { configuration. }\end{array}$ \\
\hline $\begin{array}{l}\text { Operating \& } \\
\text { Changing }\end{array}$ & $\begin{array}{l}\text { Service System to Usage - Sustainably operate the service system with the ICT- } \\
\text { enabled service innovation and without problems associated with technology and } \\
\text { new processes. }\end{array}$ \\
\hline Value capture & $\begin{array}{l}\text { Usage to Value Increase - Systematically derive benefits from the ICT-enabled } \\
\text { service innovation. This includes the measuring of the performance. }\end{array}$ \\
\hline
\end{tabular}

The second dimension of the analytical framework is derived from the constituting parts of the service system definition (Maglio et al. 2015), meaning people, information, organizations, and technologies. Thus, both dimensions combined include the service innovation process for all parts of the service system. Due to the used definition of service innovation, this composition enables an assessment of the different areas of the service system and service innovation. The actual thematic analysis consists of mapping the main research objectives and research findings of the found papers to the analytical framework.

In three steps of our research process, we used quality assessments to ensure complete and relevant results. Three senior researchers, who were not involved in the writing process of the paper, provided feedback on the respective steps. These researchers come from the research disciplines involved in the research process. First, we discussed the selection of journals. Based on their feedback, three journals were included and eight were excluded. Second, we discussed the search parameters. Based on the feedback, the assessment whether a paper includes ICT-enabled service innovations and HCSSs was performed in an extra step instead of being included in the search parameters. Third, we discussed the resulting assignments to the categories based on the objective of the papers. The feedback helped to define the main categories and assign the included papers. Thus, it allows verifying the found research gaps (Müller-Bloch and Kranz 2015).

\section{Findings}

\section{Descriptive Findings}

On the basis of the keyword, backward, and forward search, a total number of 37 papers was found in the different journals that matched the inclusion criteria. Table 2 shows the result of the literature review process. This includes the analyzed disciplines, the associated journals including the database source, the number of hits within the keyword search of the journals, the number of papers that were selected on the basis of the inclusion criteria, and the number of papers added based on the forward and backward search. It is worth remarking that the papers were mainly from journals of the fields of service research and IS. Only two of the contributions came from the field of management science and three from that of innovation management. With eight contributions, the European Journal of Information Systems was the journal with the highest number of papers in the analysis. The number of papers on the subject of ICT-enabled service innovations in HCSSs has increased in recent years. However, a clear trend cannot be confirmed. Figure 2 shows a bar chart with the number of publications for each year in which papers were found. The first contributions published in the years 1999 to 2003 are rather explorative than specific. The contributions by Broadbent et al. (1999), Uchupalanan (2000), and Bannister (2001) included empirical research in the form of case studies. The first quantitative study is the contribution of Levenburg and Klein (2006). 
Table 2. Result of the Literature Review Process.

\begin{tabular}{|c|c|c|c|c|c|}
\hline Discipline & Journal & $\begin{array}{l}\text { Source/ } \\
\text { Database }\end{array}$ & Hits & Included & $\begin{array}{l}\text { Forward/ } \\
\text { Backward }\end{array}$ \\
\hline \multirow[t]{3}{*}{$\begin{array}{l}\text { Management } \\
\text { Science }\end{array}$} & Academy of Management Journal & $\begin{array}{l}\text { Academy of } \\
\text { Management }\end{array}$ & 1 & o & \\
\hline & Journal of Management & SAGE & 1 & o & \\
\hline & Management Science & INFORMS & 3 & 1 & 1 \\
\hline \multirow[t]{10}{*}{$\begin{array}{l}\text { Information } \\
\text { Systems }\end{array}$} & $\begin{array}{l}\text { European Journal of Information } \\
\text { Systems }\end{array}$ & ProQuest & 13 & 8 & \\
\hline & Information Systems Journal & Wiley & 11 & 3 & \\
\hline & Information Systems Research & ProQuest & 4 & o & \\
\hline & $\begin{array}{l}\text { Journal of the Association for } \\
\text { Information Systems }\end{array}$ & $\begin{array}{l}\text { INFORMS / } \\
\text { ProQuest }\end{array}$ & 9 & o & \\
\hline & $\begin{array}{l}\text { Journal of Information } \\
\text { Technology }\end{array}$ & ProQuest & 9 & o & \\
\hline & $\begin{array}{l}\text { Journal of Management } \\
\text { Information Systems }\end{array}$ & Taylor \& Francis & 12 & 2 & \\
\hline & $\begin{array}{l}\text { Journal of Strategic Information } \\
\text { Systems }\end{array}$ & Science Direct & 6 & o & \\
\hline & MIS Quarterly & AIS eLibrary & 9 & 2 & \\
\hline & Electronic Markets & Taylor \& Francis & & & 2 \\
\hline & $\begin{array}{l}\text { International Journal of } \\
\text { Information Management }\end{array}$ & Science Direct & & & 1 \\
\hline \multirow{6}{*}{$\begin{array}{l}\text { Service } \\
\text { Science }\end{array}$} & Journal of Service Research & SAGE & 30 & 5 & \\
\hline & Journal of Service Management & Emerald & 22 & 3 & \\
\hline & Journal of Retailing & Science Direct & 5 & 1 & \\
\hline & $\begin{array}{l}\text { Manufacturing \& Service } \\
\text { Operations Management }\end{array}$ & ProQuest & 4 & 1 & 1 \\
\hline & Service Science & INFORMS & 35 & 2 & \\
\hline & $\begin{array}{l}\text { Journal of the Academy of } \\
\text { Marketing Science }\end{array}$ & ProQuest & & & 1 \\
\hline \multirow{6}{*}{$\begin{array}{l}\text { Innovation } \\
\text { Management }\end{array}$} & Industry and Innovation & Taylor \& Francis & 2 & $\mathrm{O}$ & \\
\hline & $\begin{array}{l}\text { Journal of Product Innovation } \\
\text { Management }\end{array}$ & Wiley & 17 & o & \\
\hline & $\begin{array}{l}\text { International Journal of } \\
\text { Innovation Management }\end{array}$ & World Scientific & 4 & 1 & \\
\hline & Research Policy & Science Direct & 11 & o & \\
\hline & Technovation & Science Direct & 25 & 2 & \\
\hline & & & 233 & 31 & 6 \\
\hline Total & & & & & 37 \\
\hline
\end{tabular}




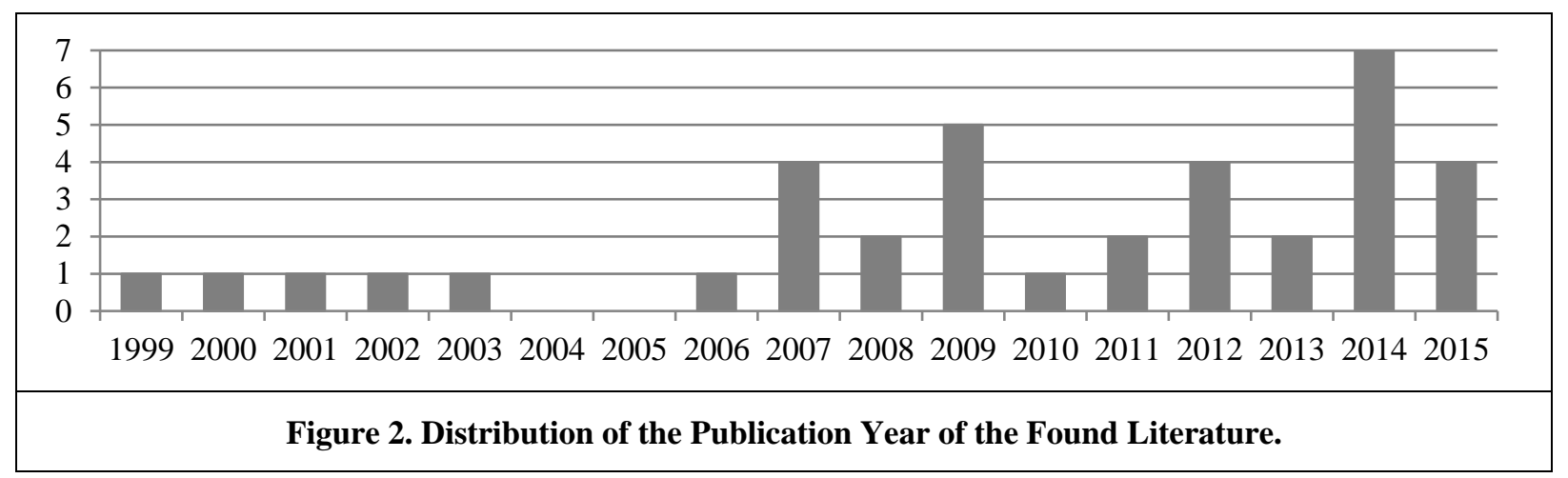

The examined contributions included empirical data from various application contexts and data sources. Table 3 shows the number of publications regarding the different research contexts. Healthcare is the most popular research context in the sample. In this industry, many of the service systems are based on the interaction between providers and patients (Bhargava and Mishra 2014; Morgre et al. 2009; Srivastava and Shainesh 2015). When considering the used research methodology (Table 4), it becomes clear that different research methods are used to examine ICT-related service innovations in HCSSs. Case study research was mostly used in the studied papers. On the one hand, authors of case studies justify their explorative approach with the complexity of service systems and the little knowledge about the research area of service systems. On the other hand, the numbers show that it is possible to examine specific aspects with quantitative methods.

\begin{tabular}{|l|l|}
\hline \multicolumn{2}{|c|}{ Table 3. Research Context of the Found Literature. } \\
\hline Industry & Found Papers \\
\hline Healthcare & 11 \\
\hline Retail & 8 \\
\hline Multiple & 4 \\
\hline Banking & 4 \\
\hline Education & 3 \\
\hline Government & 4 \\
\hline Consulting & 1 \\
\hline Hospitality & 1 \\
\hline Industry Neutral & 1 \\
\hline Total & $\mathbf{3 7}$ \\
\hline
\end{tabular}

The found literature covers different domains with diverse levels of theoretical background knowledge. On the one hand, many of the papers relate to previous research without using concrete and established theories. Examples of this approach are theoretical backgrounds on service innovation (Yang and Hsiao 2009), new service development (Lin and Hsieh 2014; Wallin et al. 2015), or the cocreation of value (Komulainen et al. 2007; Villarroel Ordenes et al. 2014). This approach was chosen in 15 of the 37 papers. On the other hand, complex theories were used when specific subsections of a problem had been studied. With regards to the theories, the unified theory of acceptance and use of technology or components thereof (technology acceptance model, theory of reasoned action) is the one most commonly used. The theories that include factors that have an impact on the usage intention and behavior were used in ten papers. Other theories that were used more than once are the task-technology fit theory ( 3 times) and the customer contact theory (2 times). 
Table 4. Research Methodology of the Found Literature.

\begin{tabular}{|l|l|}
\hline Research Methodology & Found Papers \\
\hline Case Study Research & 13 (6 Single Case Studies, 7 Multiple Case Studies) \\
\hline Mixed Methods Research & 6 \\
\hline Survey Research & 10 (6 Cross-Sectional Surveys, 4 Longitudinal Surveys) \\
\hline Experimental Research & 3 (1 Lab Experiment, 1 Field Experiment, 1 Online Experiment) \\
\hline Archival Research & 2 \\
\hline Ethnography Research & 1 \\
\hline Design Science Research & 1 \\
\hline Grounded Theory & 1 \\
\hline Total & $\mathbf{3 7}$ \\
\hline
\end{tabular}

\section{Thematic Findings}

The thematic analysis resulted in mapping the papers to the four phases of the management process and the components of the service systems definition. The individual contributions were mapped to an analytical framework due to their research objectives that are given in the paper abstract or introduction. For clarity, the results are presented by the management process and discussed regarding the individual phases of the process and the components of the service system. If the authors of the found papers discussed more than one research problem or had several findings, they can occur more than once in the discussion. The results for each of the process phases are shown in Tables 5-8.

The first phase of the proposed management process is the initiation of ICT-related service innovations in HCSSs. The papers included regarding this phase answer the question of what has to be considered for ICTenabled innovations (Table 5). Based on the number of papers, this is the most popular topic in research. Also, regarding content, it is the most comprehensive phase.

\begin{tabular}{|l|l|}
\hline \multicolumn{2}{|c|}{ Table 5. Found Literature regarding the Understanding. } \\
\hline People & $\begin{array}{l}\text { Burke (2002), Cocosila (2013), Pramatari and Theotokis (2009), Smith et al. (2014), } \\
\text { Wallin et al. (2015), Wünderlich et al. (2012) }\end{array}$ \\
\hline Information & Jahng et al. (2007), Essén (2009) \\
\hline Organizations & Bigdeli et al. (2013), Tallon (2010), Uchupalanan (2000) \\
\hline Technology & Broadbent et al. (1999), Peng et al. (2014), Komulainen et al. (2007) \\
\hline
\end{tabular}

Focusing on the individuals, the authors analyzed the impact of attitudes, beliefs, personality traits, and perceptions. Thereby, the papers include different aspects that have to be considered for ICT-related service innovations. The beneficiaries of the ICT are the research objects. Acceptance of the ICT is the main focus that is examined. For example, Cocosila (2013) examined if the attitude of beneficiaries toward the activity supports or influences the acceptance of ICT in HCSSs. She showed that there is only a small positive influence on the behavioral intention associated with using the ICT-enabled service system. Wünderlich et al. (2012) examined the attitudes toward and the use of ICT-enabled service systems while identifying a set of acceptance and usage barriers and drivers. They found that the beneficiaries' beliefs about the control over, the trustworthiness of, and collaboration with other organizations in HCSSs are important. Smith et al. (2014) analyzed factors that enable and impede the utilization of radio-frequency identification (RFID)enabled systems. They found that the utilization is affected by the perceived usefulness and the privacy concerns of the users. In order to include the system level, Pramatari and Theotokis (2009) examined the different levels of acceptance for an integrated service system including ICT. Based on an example of RFID use, they showed that personality traits such as technology anxiety and privacy concerns affect the attitude toward the use of such systems on a technology and system level. Considering other important factors on the individual level, Wallin et al. (2015) pointed out the importance of analyzing the contextual value for a 
variety of relevant stakeholders and of identifying the key persons. Burke (2002) investigated aspects of experience that are important for beneficiaries of the ICT-enabled shopping system. He emphasized that the applications and their embedding in the service system have to be generated based on the unique requirements of customer segments and product categories to ensure satisfaction.

Two contributions promote the understanding of the interaction and show the shared information in the service system. From a general perspective, Essén (2009) wanted to understand if the innovation process in HCSSs is predictable and can be controlled. She found that such innovations are nonlinear and emergent processes that can reorganize the information flow in the organization. Jahng et al. (2007) analyzed consumers' interactions on an electronic commerce platform with sold products and sales representatives. They found that the shared information of ICT-related service innovations is higher if the HCSSs are highly complex. Based on the assumption that interaction means value cocreation in HCSSs, these findings are advantageous.

At the organizational level, the authors showed how ICT-related service innovations influence their service business externally and internally. The examined factors help to understand service innovations. They are influenced by new technological resources, institutional constraints, feedback, and repurposing of available resources. Since the innovation process is greatly influenced externally, Uchupalanan (2000) wanted to explain how the characteristics of market competition affect the innovation process. He examined the relationships between competitive strategies and ICT-related innovations in financial service and found that they affect each other and depend on the context. Providing an example for the dependency, Tallon (2010) showed that there are size-related differences. ICT-related service innovations in HCSSs cannot be successfully implemented without knowing the influencing variables. The extent to which ICT and business strategy match can influence the outcome. Smaller companies should follow other strategies than large companies. Returning to a system perspective, Bigdeli et al. (2013) showed that interaction between government organizations is influenced by the combination of environmental, organizational, business process, and technological factors when using an ICT-enabled service innovation. Their intention was to show decision makers the importance of these influential factors.

Examining the mechanisms of technology, some authors focused on its role regarding service innovation. Broadbent et al. (1999) researched the links between firm-wide IT infrastructure and business process change. They found that the IT infrastructure capability has an impact on the speed and nature of process change and thus on innovation adoption. Additionally, Peng et al. (2014) focused in their paper on the aspect of technology diffusion. They proposed a framework that explains the adoption of ICT-related innovations and the influencing factors. They found that knowledge flow plays a key role in fostering technology diffusion in the first years. On the other hand, there are factors in the company that influences the technology diffusion. Komulainen et al. (2007) showed that the perception of value differs for companies according to the willingness and ability to use the ICT-related service innovations. Therefore, they advised developers and facilitators of ICT-related service innovations to study and know the different beneficiaries they want to target.

The second phase of the management process is the designing and implementing of the ICT-related service innovations in HCSSs. The papers included regarding this phase answer the question of what is the most appropriate configuration for the service system (Table 6). No papers could be assigned to the dimensions people and shared information.

\begin{tabular}{|l|l|}
\hline \multicolumn{2}{|c|}{ Table 6. Found Literature regarding the Design and Implementation. } \\
\hline People & \\
\hline Information & \\
\hline Organizations & Lin and Hsieh (2014), Pinho et al. (2014), H.-L. Yang and Hsiao (2009) \\
\hline Technology & $\begin{array}{l}\text { Lahiri and Seidmann (2012), Levenburg and Klein (2006), Mosse and Whitley (2009), } \\
\text { Skålén et al. (2015), Srivastava and Shainesh (2015), Theotokis et al. (2008), Y. Yang et } \\
\text { al. (2011) }\end{array}$ \\
\hline
\end{tabular}

In designing ICT-related service systems, the authors regard the design of the ICT as the most important sub-category with respect to the number of contributions. The category includes papers that provide assistance regarding the compilation and level of ICT in the service system and at the different phases of 
the implementation. In their analysis of existing ICT-related service systems, Levenburg and Klein (2006) recognized an oversupply of ICT for the users. They researched how companies can select ICT for a service innovation that improves the financial success of the innovation. They found that understanding the beneficiaries' needs is central to successfully design a service innovation. Based on their findings regarding the beneficiaries' needs, they established guidelines for digitized service cocreation and presented a combination of best practices with concrete proposals for the configuration. Y. Yang et al. (2011) researched which factors have to be considered in the designing of systems to maximize the influence of, benefits from, and user responses to the ICT-enabled service system. They found that the satisfaction with ICT-enabled service innovations depends on the system quality and system usefulness, so they recommended to focus on these aspects. With the same intention of maximizing the output of ICTrelated service innovations through design, Theotokis et al. (2008) examined how much technology different service systems require. Based on the dimensions of technology readiness, they proposed a classification regarding the level of customer-technology interaction in the service system. Based on much of this knowledge, Lahiri and Seidmann (2012) examined in which phase the information gathering in the HCSS makes the most sense to design an efficient ICT artifact. They found that it improves the total turnaround time in separating information gathering and usage and relocating the task upstream in the workflow. Mosse and Withley (2009) focused on the adoption of website benchmarking techniques to design ICT artifacts. They found that the development of a classification regarding the service system and an evaluation tool is more important than looking at competitors. They concluded that innovators reflect on the ways in which ICT-enabled innovations are changing the HCSS. Skålén et al. (2015) showed an example in their case study of how ICT tools can serve as a facilitator for service innovation. They proposed a service system design using interdependent ICT tools. In advanced stages of the implementation, Srivastava and Shainesh (2015) wanted to show how ICT enables growth in service systems. They found that there are enablers (obsessive customer empathy, belief in the transformational power of ICT, continuous recursive learning, and efficient network orchestration) that support the process of adoption.

For organizations, one of the most important aspects to plan in designing new ICT-related service systems is the coordination with other organizations. Pinho et al. (2014) studied value cocreation from multiple actors' perspectives and found that for coordination, the interactions in nonlinear relationships are essential. Their study emphasizes the need for designing the cocreation among different actors in the network. Lin and Hsieh (2014) analyzed new service developments in complex service systems. In addition to the identification of clear user needs and the involvement of a developed ICT in the innovation process, they found that sharing information across organizational boundaries is essential for the design of the service system. Also, regarding the new service development, H.-L. Yang and Hsiao (2009) showed mechanisms of different development phases. They showed that ideas, requirements, and specifications of the service system stimulate the development of ICT-enabled service systems in organizations

The third phase of the process is the managing of the ICT-related service innovations in HCSSs. The papers included regarding this phase answer the question of how to operate and change the service system (Table 7). No papers could be assigned to the dimension people.

\begin{tabular}{|l|l|}
\hline \multicolumn{2}{|c|}{ Table 7. Found Literature regarding the Operation and Change. } \\
\hline People & \\
\hline Information & $\begin{array}{l}\text { Breidbach et al. (2012), Tan and Pan (2003), Villarroeol Ordenes et al. (2014), Padgett } \\
\text { and Mulvey (2007) }\end{array}$ \\
\hline Organizations & Flynn and Du (2011), Padgett and Mulvey (2007), Skålén et al. (2015) \\
\hline Technology & Smith et al. (2014) \\
\hline
\end{tabular}

Managing ICT-enabled service systems is about knowing operating principles and adapting the service system to changing beneficiary needs. Working with an implemented service system, Smith et al. (2014) recognized that the usage of ICT-enabled service innovations involves more than just providing the technology. They examined relevant factors for the user acceptance of the technology (here: RFID). To improve the ICT usage, they suggested providing customers with a clear message about the benefits of using ICT. 
Focusing on the operation of the service system, interaction is particularly important when the ICT is relatively new in the service segment (Padgett and Mulvey 2007). Tan and Pan (2003) provided an example of how a governmental organization can adapt to the dynamics involved in ICT-enabled service innovation. They showed how customer relations in an organization-stakeholder relationship could work. From this, they derived lessons learned about how to change customer relationships and offer a better interaction. Following this topic, Villarroel Ordenes et al. (2014) examined the rising complexity of feedback management. They recognized that the ability to use customer interactions is related to successful cocreation processes in a service system. Thus, they proposed a linguistics-based tool that allows the analysis and improvement of feedback to customers. Contradicting the claim of managing interaction with ICT, with their findings, Breidbach et al. (2012) proposed a system that is based on human interaction. They found that ICT alone does not influence human behavior, goals, or motivations regarding the value cocreation process. They regarded managing the social connectivity between the participants of a service system as a prerequisite for a successful ICT-enabled service system.

Flynn and Du (2011) examined a related topic on an organizational level when they analyzed the legitimation process to gain stakeholder support for an ICT-enabled service innovation project. They found that monitoring and evaluating is a dynamic process that links planned interaction and an action for legitimation. Related to Smith et al. (2014), they suggested to develop an appropriate image of the system for the stakeholders and to show the progress of the development. When the service system is running, the organization finds itself in a situation where it has to differentiate itself from other competitors. Padgett and Mulvey (2007) analyzed how firms integrate ICT-related service innovations into existing service systems and align themselves in comparison to their competitors. They proposed a positioning via service interaction, customer values, or linking the technology to customer values, always in relation to the customers. Skålén et al. (2015) showed another perspective. They examined the rise of a complex ICTrelated service system and proposed actors, actions, roles, and operating principles for an unstructured process. Thus, they provided a best practice example for managing the involved organizations where uncertainty prevails.

The fourth phase of the management process is the measuring of the ICT-related service innovations in HCSSs. The papers included regarding this phase answer the question of how to prove the impact of ICTenabled service innovation (Table 8). No papers could be assigned to the dimension organization.

\begin{tabular}{|l|l|}
\hline \multicolumn{2}{|c|}{ Table 8. Found Literature regarding the Value Capture. } \\
\hline People & Ahearne et al. (2008), Bhargava and Mishra (2014), Xue et al. (2007) \\
\hline Information & Villarroel Ordenes (2014) \\
\hline Organizations & \\
\hline Technology & Bannister (2001), Piccoli and Lui (2014), Resatsch et al. (2008), Torkzadeh et al. (2011) \\
\hline
\end{tabular}

The evidence of the impact of an ICT-enabled service innovation on the individual level is essential for companies. Ahearne et al. (2008) used a salesforce example from the pharmaceutical industry to look into the mechanisms by which such an ICT-enabled service innovation can support employees to achieve their performance goals. Their findings clarify that ICT can have an impact on the key objectives and that this should be taken into account for the measurement. Similarly, Bhargava and Mishra (2014) examined the impact of an ICT-related service innovation on physician productivity. With their approach, they first analyzed the specifics of the service system, then being able to make an opinion about the productivity curve. Their findings draw attention to the influence of learning effects on the falsification of the results in the introductory phase. The paper also deals with the fact that users expect a productivity loss because of the ICT-related service innovation. The procedure explained in the paper can offer a template to refute this presumption. Based on the cocreation in the service system, the customers are a critical variable that should be measured. Xue et al. (2007) discussed the measurement of customer efficiency in self-service channels. They showed that the measurement requires identifying the influencing factors for the customer. Furthermore, they pointed out that the relationship between co-production and firm performance is an important one.

Likewise, the effectiveness of ICT components in service innovations have to be proven. This is the case in public administration. Bannister (2001) examined a service system with an unintegrated ICT. The problem 
was mainly to justify the value of the ICT introduction in the service system. Facing limited resources in the public sector, he proposed a new approach based on the concept of business objects to provide evidence for value creation through an ICT-enabled service innovation. In the private sector, it is especially important to examine the differences between the various competitors, as it was also examined by Padgett and Mulvey (2007). Piccoli and Lui (2014) analyzed the impact of ICT on the sustained competitive performance of the service system. They found that no general statements could be made regarding this connection, but found an impact of complementary resources on the ICT performance. Based on previous findings, Torkzadeh et al. (2011) studied the relationship between technology-enabled job learning and technology outcomes. They conceptualized technology outcomes with relevant variables for their context and thus demonstrated an example of a reliable, valid, and easy way to use the measurement. Also, the question of how the measurement takes place was examined. Resatsch et al. (2008) evaluated an ICT prototype in a retail context and found an approach to evaluate user acceptance. They proposed a mixed evaluation for that context.

As the only publication found, Villarroel Ordenes et al. (2014) also focused on value capture of shared information and, in particular, interactive service experiences. They proposed a framework to assess the impact of interactive service processes on customer experiences. To measure the interaction, they focus on a process rather than an output perspective.

\section{Discussion and Future Research}

The results show a diverse field of topics and growing interest in ICT-enabled service innovations in the research context of HCSSs. The understanding of the subject as a whole and in detail is most frequently discussed, whereas the value capture was the least researched. The thematic analysis shows that the numerical distribution also reflects the body of knowledge. There are more insights regarding the beginning of the management process than the end.

In the next paragraphs, we discuss the findings based on the phases of the service innovation management process. This is possible as both, quantitative and qualitative assessments of the papers are available. Table 9 provides a summary of the progress in the various fields of research. The Harvey Balls indicate how developed a research field is regarding number and content of the respective contributions. Fields, where no research had been found, were classified as very low. Fields in which only a few items were found or the contributions represent only a first attempt to research were classified as low. Fields with some contributions or fundamental findings were classified as moderate. Fields with several contributions and fundamental findings were classified as high. Fields that have already been fully covered (very high) were not found. In connection with the descriptive and thematic findings, this assessment provides the opportunity to make an assumption about the need for further research. In each thematic discussion, research gaps are localized and characterized. Thus, we follow the framework of Müller-Bloch and Kranz (2015). Also, practitioners get a structured overview of existing knowledge in the field of ICT-enabled service innovation in HCSSs.

Table 9. Summary of Research Progress.

\begin{tabular}{|l|c|c|c|c|}
\hline & People & Information & Organizations & Technology \\
\hline Understanding & 0 & 0 & 0 & 0 \\
\hline Designing \& Implementing & $\bigcirc$ & $\bigcirc$ & 0 & 0 \\
\hline Operating \& Changing & $\bigcirc$ & 0 & 0 & 0 \\
\hline Value Capture & 0 & 0 & $\bigcirc$ & 0 \\
\hline \multicolumn{2}{|c|}{$\bigcirc_{\text {Very Low }}$} \\
\hline
\end{tabular}

The papers of the understanding phase provide insights into basic considerations before implementing the ICT-enabled service innovation. It appears that much knowledge about influencing factors regarding the individual acceptance and the usage of ICT-related service innovations exists. This is reflected in complex research models (Cocosila 2013; Pramatari and Theotokis 2009; Smith et al. 2014). However, these contributions can only deal with small parts of the research field. The respective context determines much 
of the current knowledge. Therefore, they have a limited validity in a diverse research field such as HCSSs. Understanding the mechanisms related to ICT and interactions in HCSSs and doing so at a higher level appears to be rather limited. Essén (2009) attempted to illustrate the innovation process and found many influence factors. Again, the diversity of HCSSs plays a role. Overall, it could be shown that the understanding phase does not include much successive research. With their various contributions, the authors are trying to put the research phenomenon of ICT-related service innovations into a theoretical framework. Further research needs are evident regarding the points of:

- Understanding the innovation processes. There are unclear mechanisms in all fields that affect the nonlinear innovation process (Essén 2009). Clarity about the innovation process could help all actors in the service system structure their actions. Also, it could be a starting point for the designing and implementation during the next phase. The first link to research could be an analysis of the interaction between organizations in the service system. Researchers could examine the origin of the ideas for ICT-enabled service innovations. The next step could be the identification of different innovation processes to recognize patterns. This should be done in different contexts and usage perspectives to make general statements. Concrete research questions could be: What steps are included in the service innovation process? Are there domain-specific differences in the service innovation process? Which factors can influence the success or failure of the service innovation process? How does other factors like capabilities, change, and engagement influence the service innovation process?

- Understanding the ICT and interaction perspective. Previous papers do not allow general statements about these two points, and the understanding is rather limited. This is mainly based on the mixed value contributions of the components in service systems. Research on the mechanisms of ICT and shared information could enable a more effective design and management. A starting point would be to examine the contributions of the individual parts of the service system, similar to the research of Breidbach et al. (2012) who showed the differences of the contributions between people, interaction, and ICT. Smith et al. (2014) recognized this research gap. Concrete research questions could be: How does ICT influence the service innovation process? How does interaction influence the service innovation process? What value contribution do the individual components of the service provision system provide for the service innovation?

The contributions regarding the designing and implementing phase provide insights into possible configurations of the service systems. Here, the ICT design is the focus of the discussion, which it is also in other contributions (Breidbach and Maglio 2015). The level of ICT and the assistance of the value creation in service systems appear to be important factors for the value creation. Furthermore, value creation seems to be the decisive factor regarding the design of the service system. The findings and the contributions of Skålén et al.(2015) are the first insight. The individual beneficiary has thus far not been considered in research. The same applies to the design of shared information in the service system. Existing findings also show that designing the coordination of organizations is complex (Pinho et al. 2014). Overall, there are only a few general design guidelines. Further research needs are evident regarding the points of:

- Designing the service system on the basis of value creation. The findings of Levenburg and Klein (2006) and Theotokis et al. (2008) show the need for decision-making on the basis of user needs. When considering the whole service system, the user needs probably fall short. As a first step, investigating the contributions of ICT in a service system would generate a general design guideline. Based on this, having design guidelines for the entire service system would certainly be helpful, which ensures completeness with respect to the entire service system and take the value creation into account. Concrete research questions could be: How to design the interfaces of service systems and service innovation? How to design the interfaces of service systems and corresponding concepts in service innovations? How to include the beneficiary in service innovation to increase value creation? Which guidelines or rules should be respected in the design of the service innovation? How to optimize value creation in service innovation?

- Designing roles and interaction in HCSSs. In addition to the role of the ICT in a service system, the contribution of Breidbach et al. (2012) showed the importance of human interaction in HCSSs. This is a topic that has not been researched regarding the design of HCSSs. A first approach would be to summarize existing approaches of other fields. Furthermore, it would be interesting to find out what differentiates roles and interaction in HCSSs. Based on the findings, the designing 
could take place. Pinho et al. (2014) recognized this research gap as they regard interaction as an important function for the coordination of the involved organizations. Concrete research questions could be: How to design human interaction in ICT-enabled service system? What differentiates roles and interaction in ICT-enabled HCSSs? What roles are important in ICT-enabled HCSSs? How to leverage interaction in the design of ICT-enabled HCSSs?

In the analyzed literature, the operating and changing phase provided insights into management and adaptation practices. Ideally, these papers contain guidelines, which can be easily adopted by managers within the running service system. However, there are not many of those contributions. It seems that findings regarding the understanding and designing phase have not been implemented in service systems. Thus, they cannot provide specific advice regarding the management of ICT-enabled service innovations. A variety of papers of the operating phase examined the phase that follows shortly after the implementation of the service innovation (e.g., Flynn and Du (2011) or Padgett and Mulvey (2007)), which could be an indication of an underdeveloped design. Moreover, it is noteworthy that personal connections and information between individuals play an important role in addition to the technology (Breidbach et al. 2012; Smith et al. 2014). Further research needs are evident regarding the points of:

- Managing people in the service system. Individuals cocreate value in service systems (Vargo and Lusch 2016). If these individuals can be encouraged to become more integrated into ICTenabled service innovation processes, value creation can be enabled. The starting point would be to have guidelines about how to involve employees or third parties such as volunteers in the ICTenabled service systems. Here, ideas from Operations could be helpful such as the customer contact theory (Chase 1981). Additionally, an alignment with value creation and the productivity of the service system should be ensured. Concrete research questions could be: How to integrate beneficiaries in ICT-enabled service systems? How to increase human-based value creation in ICTenabled service systems? How to align value creation and productivity in ICT-enabled HCSSs?

- Managing dynamics of the service system. After the initial implementation and set-up, the service system should create value for the beneficiaries. It is important to adapt the service system to the changing needs of the beneficiaries to ensure this value creation. Essén (2009) showed an example of how this can be done in real life. Further research is needed to capture the changing needs and to implement them in the service system. A template for this could be the work of Lin and Hsieh (2014), who considered these dynamics regarding new service development. Concrete research questions could be: How to operationalize service innovation in ICT-enabled service systems? What management is needed in the shakedown phase of ICT-enabled service innovation? What changes are needed in service innovation to enable value creation in the service system?

The papers of the measuring phase provide insights into how the effectiveness can be examined. All contributions define the metrics matching their contexts. The literature recognized that the output of the service system does not solely depend on the employees, but also on the customers (Xue et al. 2007); and this does not only need to be measured within the company but can also be compared with competitors (Piccoli and Lui 2014). Interestingly, there are influencing factors such as the learning curve of users (Bhargava and Mishra 2014) that some of the authors took into account and others did not. It can be assumed that the exclusion is a simplification of the reality. It is also interesting that with their contribution, Torkzadeh et al. (2011) are the only ones who thought about the effectiveness of their introduced metrics. Research needs are evident regarding the points of:

- Measuring interaction in the service system. The focus of many of the contributions is the measurement of the output variables. Here, the interaction and the value cocreation are difficult to measure. As service is a process (Vargo and Lusch 2004), it is also important to examine the contribution of HCSSs in a new way. The perspective of Villarroeol Ordenes et al. (2014) recognized this research gap. Based on this, a complete measurement and control system for ICT-enabled service innovations in HCSSs could be developed. Concrete research questions could be: What do influence interaction in ICT-enabled HCSSs? How to implement value capture from interaction in ICT-enabled HCSSs? How to measure value cocreation in HCSSs?

- Measuring the contribution of organizations. Organizations are basic constituents of a service system. A service system can create value when multiple organizations work together by performing coordinated activities. If a service system is to be optimized, it is interesting to know which contributions the individual organization adds for the value creation. Research in this area 
could reveal mechanisms, reduce coordination efforts, and capture the value cocreation of the entire service system. Concrete research questions could be: How to measure value contribution of participants in the service system? What coordination tools can be leveraged in ICT-enabled HCSSs? How to optimize coordination in the service system?

\section{Limitations}

As in any literature review, this review faces limitations. These are the restricted scope of the literature review, the selection of the included papers, and the extraction of the contained information. The scope of the literature review is restricted and not exhaustive. The limitation to top journals allows us to highlight the state of the art in established and high-quality research. To counteract this limitation, new and diverse research was included in the theoretical background. The limitation to papers with a focus on service systems serves the purpose of the selection of HCSSs that go beyond the service between companies and customers. The selection of the included literature is influenced by interpretation. The sources of the journals are specified in Table 2 to validate the results. Also, the selection of the included literature was not standardized. It was based on the selection criteria, but assessed by the authors. Since the review process included the selection of the found papers based on their title and abstract, the used information was limited. Both facts, the interpretive results of the databases and the selection, were minimized by including a larger number of doubtful contributions. Similar to the selection of the journals, validity and objectivity of the findings might be challenged by extraction of the included information. To achieve optimal results, we established categories for the data extraction and the analytical framework. Also, the results were discussed with independent senior researchers.

\section{Conclusion}

This literature review presented an integrated and representative overview of the literature on ICT-enabled service innovation in HCSSs and highlighted opportunities for future research. We conducted a systematic literature review and could identify 37 individual research papers that show ICT as an enabler of service innovations in HCSSs. We develop an analytical framework for the assessment of the found literature. Applying the analytical framework allowed us to show that existing contributions focus on a few topics such as the understanding of individual attitudes, beliefs, personality traits, and perceptions, and the designing of ICT artifacts in service systems. Regarding other topics, there are no or little contributions, which provides the opportunity for future research. We could also show that the research background and the research methods used in the papers are very diverse, representing a large research field with a varying degree of knowledge. In our discussion, we named eight concrete and emerging research opportunities: Understanding the innovation processes, understanding the ICT and interaction perspective, designing the service system on the basis of value creation, designing roles and interaction in HCSSs, managing people in the service system, managing dynamics of the service system, measuring interaction in the service system, and measuring the contribution of organizations. Overall, this literature review contributes to the existing literature in promoting further understanding of ICT-enabled service innovation in HCSSs of researchers and practitioners, in providing an analytical framework for ICT-enabled service innovation, and by highlighting concrete research gaps.

\section{Acknowledgements}

The research presented in this paper was partially funded by the Active and Assistive Living (AAL) programme and the Swiss State Secretariat for Education, Research and Innovation (SERI) under contract number AAL-2013-6-145.

\section{References}

Ahearne, M., Jones, E., Rapp, A., and Mathieu, J. 2008. "High touch through high tech: The impact of salesperson technology usage on sales performance via mediating mechanisms," Management Science (54:4), pp. 671-685.

Alter, S. 2008. "Service system fundamentals: Work system, value chain, and life cycle," IBM Systems Journal (47:1), pp. 71-85 (doi: 10.1147/sj.471.0071). 
Apple Inc. 2016. "Apple and education," (available at http://www.apple.com/education/; retrieved September 8, 2016).

Bannister, F. 2001. "Dismantling the silos: Extracting new value from IT investments in public administration," Information Systems Journal (11:3), pp. 65-84.

Barrett, M., Davidson, E., Prabhu, J., and Vargo, S. L. 2015. "Service innovation in the digital age: Key contributions and future directions," MIS Quarterly (39:1), pp. 135-154.

Bhargava, H. K., and Mishra, A. N. 2014. "Electronic medical records and physician productivity : Evidence from panel data analysis," Management Science (60:10), pp. 2543-2562.

Bigdeli, A. Z., Kamal, M. M., and de Cesare, S. 2013. "Electronic information sharing in local government authorities: Factors influencing the decision-making process," International Journal of Information Management (33:5), pp. 816-830.

Bitner, M. J., Brown, S. W., and Meuter, M. L. 2000. “Technology infusion in service encounters," Journal of the Academy of Marketing Science (28:1), pp. 138-149.

Breidbach, C. F., Kolb, D. G., and Srinivasan, A. 2012. "Connectivity in service systems: Does technologyenablement impact the ability of a service system to co-create value?," Journal of Service Research (16:3), pp. 428-441.

Breidbach, C. F., and Maglio, P. P. 2015. "A service science perspective on the role of ICT in service innovation," in ECIS 2015 Research-in-Progress Papers.

Broadbent, M., Weill, P., and St.Clair, D. 1999. "The implication of information technology infrastructure for business process redesign,” MIS Quarterly (23:2), pp. 159-182.

vom Brocke, J., Simons, A., Niehaves, B., Reimer, K., Plattfaut, R., and Cleven, A. 2009. "Reconstructing the giant: On the importance of rigour in documenting the literature search process," in Proceedings of the 17th European Conference on Information Systems (ECIS), Verona, Italy, pp. 2206-2217.

vom Brocke, J., Simons, A., Riemer, K., Niehaves, B., Plattfaut, R., and Cleven, A. 2015. "Standing on the shoulders of giants: Challenges and recommendations of literature search in information systems research," Communications of the Association for Information Systems (37:1), pp. 205-224.

Burke, R. R. 2002. "Technology and the customer interface: What consumers want in the physical and virtual store," Journal of the Academy of Marketing Science (30:4), pp. 411-432.

Chase, R. B. 1981. "The customer contact approach to services: Theoretical bases and practical extensions," Operations Research (29:4), pp. 698-706.

Cocosila, M. 2013. "Role of user a priori attitude in the acceptance of mobile health: An empirical investigation," Electronic Markets (23:1), pp. 15-27.

Cooper, H. M. 1988. "Organizing knowledge synthesis: a taxonomy of literature reviews," Knowledge in society (1:1), pp. 104-126.

Davis, M. M., Spohrer, J. C., and Maglio, P. P. 2011. "Guest editorial: How technology is changing the design and delivery of services," Operations Management Research (4:1-2), pp. 1-5.

Essén, A. 2009. "The emergence of technology-based service systems: A case study of a telehealth project in Sweden," Journal of Service Management (20:1), pp. 98-121.

Flynn, D., and Du, Y. 2011. "A case study of the legitimation process undertaken to gain support for an information system in a Chinese university," European Journal of Information Systems (21:3), pp. 212-228.

den Hertog, P., van der Aa, W., and de Jong, M. W. 2010. "Capabilities for managing service innovation: Towards a conceptual framework," Journal of Service Management (21:4), pp. 490-514.

Huang, M.-H., and Rust, R. T. 2013. "IT-Related Service: A multidisciplinary perspective," Journal of Service Research (16:3), pp. 251-258.

Jahng, J., Jain, H., and Ramamurthy, K. 2007. "Effects of interaction richness on consumer attitudes and behavioral intentions in e-commerce: some experimental results," European Journal of Information Systems (16:3), pp. 254-269.

Jennex, M. E. 2015. "Literature reviews and the review process: An editor-in-chief's perspective," Communications of the Association for Information Systems (36:8), pp. 139-146.

Kleinschmidt, S., Burkhard, B., Hess, M., Peters, C., and Leimeister, J. M. 2016. "Towards design principles for aligning human-centered service systems and corresponding business models," in Proceedings of the 37th International Conference on Information Systems (ICIS), Dublin, Ireland.

Komulainen, H., Mainela, T., Tähtinen, J., and Ulkuniemi, P. 2007. "Retailers' different value perceptions of mobile advertising service," International Journal of Service Industry Management (18:4), pp. $368-393$. 
Lahiri, A., and Seidmann, A. 2012. "Information hang-overs in healthcare service systems," Manufacturing \& Service Operations Management (14:4), pp. 634-653.

Levenburg, N. M., and Klein, H. A. 2006. "Delivering customer services online: Identifying best practices of medium-sized enterprises," Information Systems Journal (16:2), pp. 135-155.

Lin, F. R., and Hsieh, P. S. 2014. "Analyzing the sustainability of a newly developed service: An activity theory perspective," Technovation (34:2), pp. 113-125.

Lusch, R. F., and Nambisan, S. 2015. "Service innovation: A service-dominant-logic perspective," MIS Quarterly (39:1), pp. 155-175.

Maglio, P. 2015. "Editorial-Smart service systems, human-centered service systems, and the mission of service science," Service Science (7:2), pp. ii-iii.

Maglio, P. P., Kwan, S. K., and Spohrer, J. 2015. "Commentary-Toward a research agenda for humancentered service system innovation," Service Science (7:1), pp. 1-10.

Maglio, P. P., and Spohrer, J. 2008. "Fundamentals of service science," Journal of the Academy of Marketing Science (36:1), pp. 18-20.

Markus, M. L. 2004. “Technochange management: Using IT to drive organizational change," Journal of Information Technology (19:1), pp. 4-20.

Morgre, R., Gadh, R., Chattopadhyay, A., Mogre, R., Gadh, R., and Chattopadhyay, A. 2009. "Using survey data to design a RFID centric service system for hospitals," Service Science (1:3), pp. 189-206.

Mosse, B., and Whitley, E. A. 2009. "Critically classifying: UK e-government website benchmarking and the recasting of the citizen as customer," Information Systems Journal (19:2), pp. 149-173.

Müller-Bloch, C., and Kranz, J. 2015. "A framework for rigorously identifying research gaps in qualitative literature reviews," in Proceedings of the 36th International Conference on Information Systems (ICIS), Fort Worth, TX, USA.

OECD. 2015. "OECD digital economy outlook 2015," Paris.

Ostrom, A. L., Parasuraman, A., Bowen, D. E., Patricio, L., and Voss, C. A. 2015. "Service research priorities in a rapidly changing context," Journal of Service Research (18:2), pp. 127-159.

Padgett, D., and Mulvey, M. S. 2007. "Differentiation via technology: Strategic positioning of services following the introduction of disruptive technology," Journal of Retailing (83:4), pp. 375-391.

Paré, G., Trudel, M.-C., Jaana, M., and Kitsiou, S. 2015. "Synthesizing information systems knowledge: A typology of literature reviews," Information \& Management (52:2), pp. 183-199.

Peng, G., Dey, D., and Lahiri, A. 2014. "Healthcare IT adoption: An analysis of knowledge transfer in socioeconomic networks," Journal of Management Information Systems (31:3), pp. 7-34.

Peters, C. 2016. Modularization of services - A modularization method for the field of telemedicine, Kassel: Kassel University Press.

Peters, C., Blohm, I., and Leimeister, J. M. 2015. "Anatomy of successful business models for complex services: Insights from the telemedicine field," Journal of Management Information Systems (32:3), pp. $75^{-104 .}$

Peters, C., Maglio, P., Badinelli, R., Harmon, R. R., and Maull, R. 2016. "Emerging digital frontiers for service innovation," Communications of the Association for Information Systems (39:1), pp. 136-149.

Piccoli, G., and Lui, T.-W. 2014. "The competitive impact of information technology: can commodity IT contribute to competitive performance?," European Journal of Information Systems (23:6), pp. 616628.

Pinho, N., Beirão, G., Patrício, L., and Fisk, R. P. 2014. "Understanding value co-creation in complex services with many actors," Journal of Service Management (25:4), pp. 470-493.

Pramatari, K., and Theotokis, A. 2009. "Consumer acceptance of RFID-enabled services: A model of multiple attitudes, perceived system characteristics and individual traits," European Journal of Information Systems (18:6), pp. 541-552.

Rai, A., and Sambamurthy, V. 2006. "Editorial notes-The growth of interest in services management: Opportunities for information systems scholars," Information Systems Research (17:4), pp. 327-331.

Resatsch, F., Sandner, U., Leimeister, J. M., and Krcmar, H. 2008. "Do point of sale RFID-based information services make a difference? Analyzing consumer perceptions for designing smart product information services in retail business," Electronic Markets (18:3), pp. 216-231.

Rowe, F. 2014. "What literature review is not: Diversity, boundaries and recommendations," European Journal of Information Systems (23:3), pp. 241-255.

Ryu, H.-S., Lee, J., and Ham, J. 2014. "Understanding the role of technology in service innovation : A comparison of three theoretical perspectives," in Proceeding of the 19th Pacific Asia Conference on Information Systems (PACIS), Chengdu, China. 
Sheehan, J. 2006. "Understanding service sector innovation," Communications of the Association for Information Systems (49:7), pp. 42-47.

Skålén, P., Aal, K. A., and Edvardsson, B. 2015. "Cocreating the Arab spring: Understanding transformation of service systems in contention," Journal of Service Research (18:3), pp. 250-264.

Smith, J. S., Gleim, M. R., Robinson, S. G., Kettinger, W. J., and Park, S.-H. 2014. "Using an old dog for new tricks: A regulatory focus perspective on consumer acceptance of RFID applications," Journal of Service Research (17:1), pp. 85-101.

Spohrer, J., Maglio, P., Bailey, J., and Gruhl, D. 2007. "Steps toward a science of service systems," Computer (40:1), pp. 71-77.

Srivastava, S. C., and Shainesh, G. 2015. "Bridging the service divide through digitally enabled service innovations: Evidence from Indian healthcare service providers," MIS Quarterly (39:1), pp. 245-267.

Tallon, P. P. 2010. "A service science perspective on strategic choice, IT, and performance in U.S. banking," Journal of Management Information Systems (26:4), pp. 219-252.

Tan, C. W., and Pan, S. L. 2003. "Managing e-transformation in the public sector: An e-government study of the Inland Revenue Authority of Singapore (IRAS)," European Journal of Information Systems (12:4), pp. 269-281.

Theotokis, A., Vlachos, P. A., and Pramatari, K. 2008. "The moderating role of customer-technology contact on attitude towards technology-based services," European Journal of Information Systems (17:4), pp. 343-351.

Torkzadeh, G., Chang, J. C., and Hardin, A. M. 2011. "Usage and impact of technology enabled job learning," European Journal of Information Systems (20:1), pp. 69-86.

Uchupalanan, K. 2000. "Competition and IT-based innovation in banking services," International Journal of Innovation Management (4:4), pp. 455-489.

Vargo, S. L., and Lusch, R. F. 2004. "Evolving to a new dominant logic for marketing," Journal of Marketing (68:1), pp. $1-17$.

Vargo, S. L., and Lusch, R. F. 2016. "Institutions and axioms: an extension and update of service-dominant logic," Journal of the Academy of Marketing Science (44:1), pp. 5-23.

Villarroel Ordenes, F., Theodoulidis, B., Burton, J., Gruber, T., and Zaki, M. 2014. "Analyzing customer experience feedback using text mining: A linguistics-based approach," Journal of Service Research (17:3), pp. 278-295.

Wallin, A., Harjumaa, M., Pussinen, P., and Isomursu, M. 2015. "Challenges of new service development : Case video-supported home care service," Service Science (7:2), pp. 1-19.

Webster, J., and Watson, R. T. 2002. "Analyzing the past to prepare for the future: Writing a literature review," Management Information Systems Quarterly (26:2), pp. xiii-xxiii.

World Bank. 2016. "Services, etc., value added (\% of GDP)," (available at http://data.worldbank.org/indicator/NV.SRV.TETC.ZS).

Wünderlich, N. V., von Wangenheim, F., and Bitner, M. J. 2012. "High tech and high touch: A framework for understanding user attitudes and behaviors related to smart interactive services," Journal of Service Research (16:1), pp. 3-20.

Xue, M., Hitt, L. M., and Harker, P. T. 2007. "Customer efficiency, channel usage, and firm performance in retail banking," Manufacturing \& Service Operations Management (9:4), pp. 535-558.

Yang, H.-L., and Hsiao, S.-L. 2009. "Mechanisms of developing innovative IT-enabled services: A case study of Taiwanese healthcare service," Technovation (29:5), pp. 327-337.

Yang, Y., Stafford, T. F., and Gillenson, M. 2011. "Satisfaction with employee relationship management systems: The impact of usefulness on systems quality perceptions," European Journal of Information Systems (20:2), pp. 221-236.

Yoo, Y., Boland, R. J., Lyytinen, K., and Majchrzak, A. 2012. "Organizing for innovation in the digitized world," Organization Science (23:5), pp. 1398-1408. 